\title{
The Unacceptance of a Self-Management Health System by Healthy Older Adults
}

\author{
Ine D’Haeseleer ${ }^{1} \mathbb{C}^{\mathrm{a}}$, Dries Oeyen ${ }^{2}$, Bart Vanrumste $^{1} \mathbb{C}^{\mathrm{b}}$, Dominique Schreurs ${ }^{3} \mathbb{D}^{\mathrm{c}}$, \\ and Vero Vanden Abeele ${ }^{1}{ }^{\mathrm{d}} \mathrm{d}$ \\ ${ }^{1}$ KU Leuven, e-Media Research Lab, Belgium \\ ${ }^{2}$ BeWell Innovations, Belgium \\ ${ }^{3}$ KU Leuven, ESAT-TELEMIC, Belgium \\ \{ine.dhaeseleer, dominique.schreurs, bart.vanrumste, vero.vandenabeele\}@kuleuven.be, \\ dries.oeyen@bewellinnovations.com
}

Keywords: $\quad$ Older Adults, Self-Management Health Systems, User-study, UTAUT Acceptance Model

\begin{abstract}
Self-Management Health Systems (SMHS) are defined as systems that combine data logging via multiple sensors and/or self-reports, possibly enhanced with risk assessment and decision support. Research on SMHS is booming, particularly as it is envisioned to support ageing in place for an increasingly greying population. However, findings on what drives adoption of SMHS by healthy older adults is still lacking. Therefore, an SMHS was tested for two weeks in a real world setting by 16 healthy participants aged $65+$. We measured acceptance towards the SMHS pre and post, combined with qualitative data, and usage logs. Results indicate that at the start of the study, older adults perceived the system as easy to use, useful, and that participants had access to supporting infrastructure. Notwithstanding, behavioural intention to use an SMHS was rather low. Post usage, our findings show that, while perceived ease of use and confidence increased, perceived usefulness and behavioural intention further decreased. These findings suggest that older adults are not yet ready to adopt SMHS, and that design efforts should particularly be geared towards increasing perceived usefulness.
\end{abstract}

\section{INTRODUCTION}

The world's population is ageing; it is predicted that the number of people aged 65 years or older will double to 160 millions by 2060 (Nations, 2015). Therefore, many studies focus on older adults and technologies to support healthy ageing. In particular, Self-Management Health Systems (SMHS), i.e., integrated technical systems which combine data logging via multiple sensors and/or self-reports, e.g., surveys, logbooks, pain scales, with data visualisations, risk assessment, and decision support, have been put forward as a solution to support ageing in place (Queirós et al., 2017). Such systems are equally envisioned to support a shift to preventive care, and to empower older adults in the co-creation of their own health (Vines et al., 2015).

Many R\&D efforts are geared towards building

\footnotetext{
a (iD) https://orcid.org/0000-0001-5455-3581

b (iD https://orcid.org/0000-0002-9409-935X

c (iD https://orcid.org/0000-0002-4018-7936

d(D) https://orcid.org/0000-0002-3031-9579
}

SMHS and solving technical challenges (Doyle et al., 2014; Jiménez-Mixco et al., 2013). Various commercial and non-commercial actors are working on increasingly efficient technological systems, varying from memory training (Lumos Labs, 2020) to tracking of vital parameters (iHealth Labs Inc., 2019) e.g., blood pressure, glucose meters, or any combination. Besides tracking information, also self-reported data, e.g., (Ware and Sherbourne, 1992; Fougeyrollas and Noreau, 2001) and risk assessments, e.g., (Buckingham, 2016) are investigated and used in SMHS.

However, beyond solving technological challenges, there is also a need for further insight into the actual use and acceptance of these systems, and what drives adoption of SMHS by older adults. Studies on the adoption of related technologies for e.g., assisted living or telemonitoring show mixed results. Some studies (Sintonen and Immonen, 2013; Wang et al., 2019) show that older adults are open to the idea of managing their own health. Other studies portray a more nuanced image on acceptance of healthrelated ICT among older adults (Heart and Kalderon, 2013; Peek et al., 2016; Young et al., 2013; Verdezoto 
and Grönvall, 2016; Jaschinski and Allouch, 2015; Kononova et al., 2019; D'Haeseleer et al., 2019b). These studies indicate a lack in perceived usefulness and identify remaining barriers which needs to be addressed before adoption of SMHS by older adults. These inconsistent findings may be due to different operationalisations of what constitutes SMHS. They may also be attributed to different inclusion criteria for older adults, or different contexts-of-use - mundane versus clinical contexts (Nunes et al., 2015).

Due to the inconsistent findings, designers may lack insight into what drives the acceptance and use of SMHS by older adults, and how to design for it. In this study, we are particularly interested in community dwellers who aim to use SMHS in a mundane setting, i.e., older adults aged over $65+$, in good health and still living at home. We deemed it important to gain a deeper understanding of how this group of older adults uses SMHS by combining quantitative, qualitative, and usage data.

Therefore, we created a prototypical SMHS, including a questionnaire on health and wellbeing, an activity tracker, a blood pressure monitor, and a sleep sensor. After designing and developing the SMHS, the application was tested in a real world setting by means of a user-study with 16 self-reported healthy ${ }^{1}$ participants aged 65+, during two weeks. Acceptance of the SMHS was both measured at the beginning and at the end of the user-study, based on a questionnaire informed by the Unified Theory of Acceptance and Use of Technology (UTAUT) (Venkatesh et al., 2003). Additionally, extra information was collected through open-ended interviews and usage logs. The results suggest a lack in intention to adopt the SMSH; older adults aged $65+$ are not yet waiting for these systems.

In Section 2, an overview of related work is given. Section 3 describes the method. Section 4 presents participants' results: experience data, UTAUT evaluation, and usage data. Further, in Section 5 results are discussed and compared to findings in literature. Finally, section 6 concludes and addresses future work.

\section{RELATED WORK}

\subsection{Self-Management Health Systems}

SMHS are on the rise. Several researchers investigated the acceptance and use of SMHS by older adults (Sintonen and Immonen, 2013; Heart and Kalderon,

\footnotetext{
${ }^{1}$ Older adults that perceive themselves as healthy, but may experience mild cognitive and/or physical decline due to their age.
}

2013; Peek et al., 2016; Wang et al., 2019). Often, such studies include hundreds of participants, to allow generalising views and attitudes of the participants to a broader audience of 'older adults'. Yet, such survey studies most often remain hypothetical, as participants are not offered a salient experience of using an actual SMHS. On the other hand, studies that do include hands-on experiences through workshops or prototypes, e.g., (Kononova et al., 2019; D'Haeseleer et al., 2019b; Jaschinski, 2014; Verdezoto and Grönvall, 2016; Young et al., 2013) are mainly system evaluations that gauge technical possibilities, as well as usability issues. These studies are highly important to overcome possible barriers in developing and using SMHS, but not well suited to understand and evaluate long-term adoption.

Adoption studies with older adults do exist, but are typically not using SMHS, but rather a related ICT technology, or rely on the support of a caregiver. For example, Jiménez-Mixco et al. investigated a system to monitor health and promote active ageing by including biomedical sensors in over 100 healthy older adults (Jiménez-Mixco et al., 2013). Results were promising regarding usability and usefulness, and moreover, most of the participants (68\%) wanted to use the application in the future. However, older adults in this study were relatively young (aged $55+$ ). Moreover, the study did not focus on the selfmanaging of health, as they still relied on the support of a caregiver. Another study from McMahon et al. investigated the use and acceptance of older adults, aged 70+, towards physical activity trackers (McMahon et al., 2016). In total, 95 older adults participated in an intervention study of 8 months. At the end of the study, participants were asked about their experiences. Ratings were twice positive, nevertheless, they did decrease in the second measurement. Researchers also found that the oldest older adults $(80+)$ were less positive than those aged between 70 and 80 .

To the best of the authors' knowledge, there is only one adoption study on using SMHS by older adults. Doyle et al. investigated attitudes and adherence to wellness self-management in older adults (Doyle et al., 2014). The sample was limited to seven participants (mean age $=70.6$ ), who tested the application. After two months the trial period was over and participants were free to continue or quit using the application (one person quit). After five months, participants were interviewed to learn about their experiences. Results showed that the application was found user-friendly, and participants were intrinsically motivated to use it. Participants particularly emphasised the importance of receiving feedback from the system. 


\subsection{Technology Acceptance Theories}

There are several psychological theories that investigate user acceptance and adoption of technologies, e.g., (Champion et al., 2008; Fishbein, 1979; Deci and Ryan, 2012; Davis, 1985; Venkatesh et al., 2003). The model underlying this study is the "Unified theory of acceptance and use of technology" (UTAUT) (Venkatesh et al., 2003). This model has been put forward as the gold standard of technology adoption (Taiwo and Downe, 2013). UTAUT was first used in general IT adoption within a work environment. Yet since, several studies have used and extended UTAUT to health care technologies, e.g., (Peek et al., 2019; Vanneste et al., 2013; Khechine et al., 2016; Cimperman et al., 2016), and portrayed it as a fitting theory also in a health care context. According to UTAUT, four key constructs are used to assess behavioural intention (i.e., acceptance) to use a system:

1. Performance Expectancy (PE) or "Do I find the system useful?"

2. Effort Expectancy (EE) or "How difficult do I find it to use the system?"

3. Social Influence (SI) or "What will others think about me when using the system?"

4. and Facilitating Conditions (FC) or "Do I have the facilities/technologies in order to use the system?"

The UTAUT model upholds that these constructs are determinants of the behavioural intention to use the system and can be used to predict the actual use (see figure 1). In other words, by measuring these four constructs, one can predict the Behavioural Intention (BI) of the user to adopt, and use the system.

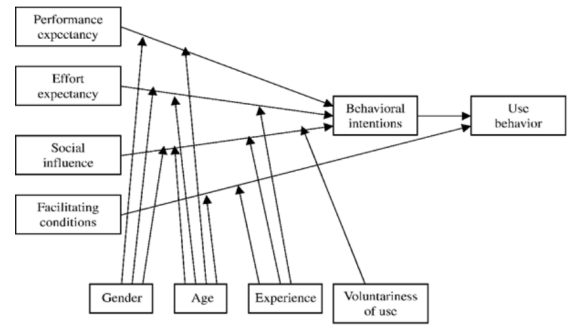

Figure 1: UTAUT model by (Venkatesh et al., 2003).

However, most recent studies focusing on adoption of health care technologies that involve capturing data from users, by means of sensors and/or selfreports, showed that additional constructs such as 'anxiety' or 'safety of data' may also play an important role in the use and acceptance of technologies (Ebert et al., 2015; Baumeister et al., 2014). Hence, in more recent UTAUT models for a health care context, these constructs can be added (De Witte and Van Daele, 2017).

\section{METHOD}

To explore the attitudes of older adults towards one particular SMHS, we conducted a user evaluation with 16 participants (ten women and six men) for a two-week study. These studies took place between July and November 2018.

\subsection{SMHS Application with Sensors}

For this study, an application was designed for older adults to fill out questionnaires, view their answers to the questionnaire's items, along with results measured by three different sensors: activity tracker, sleep monitor, and blood pressure monitor.

The questionnaire used in this study is a combination of the RAND-36 (Ware and Sherbourne, 1992; Van der Zee and Sanderman, 1993) and Life Habits (Fougeyrollas and Noreau, 2001; Lemmens et al., 2007). RAND-36 is an assessment for health-related quality of life, divided over nine categories: physical functioning, physical role functioning, emotional role functioning, energy/fatigue, emotional wellbeing, social functioning, pain, general health, and health change. The RAND questionnaire was validated with 8117 community dwellers, ages ranging from 65-104 years old (Walters et al., 2001). Data was reported and made it possible to filter for gender and age-group, and therefore was used as an indication for 'other' participants. For our application, additionally, three categories were selected from the Life Habits: meals, sleep, and personal care. Thus in total, our SMHS consisted of 12 categories and 49 items.

The application was developed as a webapplication, optimised for tablet-use. The preferred design needed to be as simple as possible, thus limiting the amount of features available. When using the application, the home screen gives an overview of the results from the activity tracker and the questionnaires. Participants can select a topic from a questionnaire and fill out several questions. Once a category is completed, results are shown on the results page, where participants can also compare themselves to normalised data from a previous study (Walters et al., 2001). The results from the sensors are automatically synchronised with the application and can be viewed on a different screen. Different screenshots of the application are shown in figure 2.

The sensors, which were integrated in the application, consist of an activity monitor (Activ8, 2016), a sleep monitor (Beddit, 2016), and a blood pressure monitor (A\&DCompany, 2016). The activity tracker can be worn in a pocket of trousers and distinguishes activities such as 'lying down', 'standing', 'sitting', 

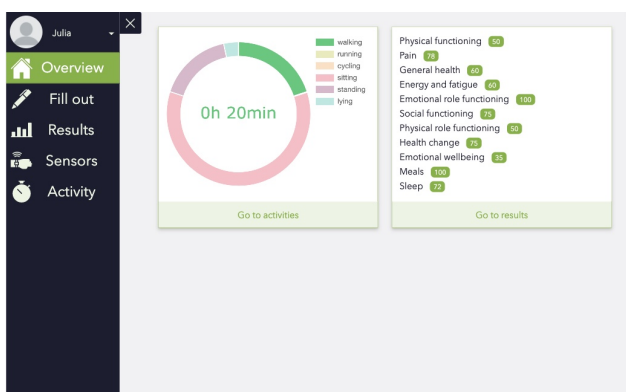

(a) Overview page.
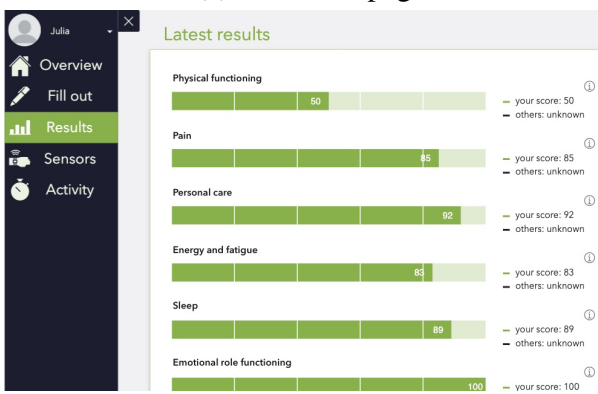

(c) Results from questionnaires.
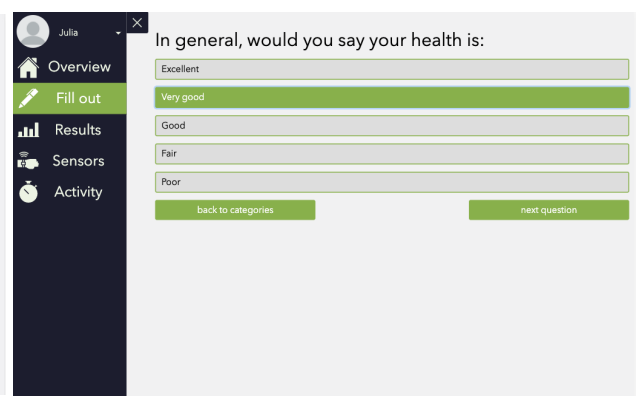

(b) Question in questionnaire.
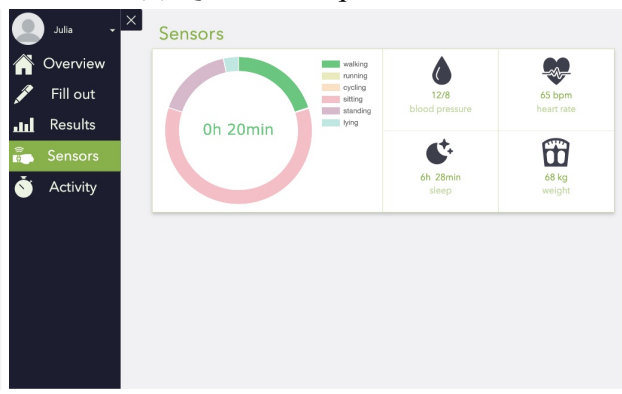

(d) Results from sensors.

Figure 2: Screenshots of SMHS application.

'walking', 'cycling', and 'running'. The sleep monitor registers how long someone sleeps, as well as the efficiency of the sleep represented by a sleep score. The blood pressure monitor captures the systolic and diastolic pressure as well as the pulse. Data from the sensors were collected via BeWell Innovations (Innovations, 2016) and automatically, through an API, integrated and visualised in the SMHS.
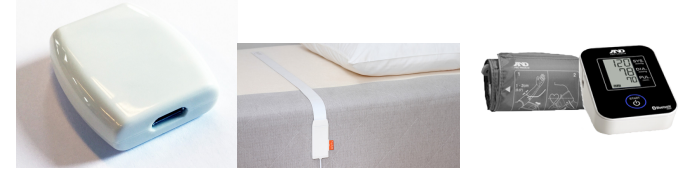

(a) Activ8 activ-(b) Beddit sleep (c) A\&D blood ity tracker. monitor. pressure monitor.

Figure 3: Integrated sensors in SMHS.

\subsection{Measurement Instrument}

To measure use and acceptance of the SMHS, we relied on the Dutch variant of the questionnaire based on Ebert et al. (Ebert et al., 2015), translated by De Witte and Van Daele (De Witte and Van Daele, 2017). This Dutch questionnaire polls for seven drivers: performance expectancy (PE), effort expectancy (EE), social influence (SI), facilitating conditions (FC), anxiety (ANX), safety (SAF), and behavioural inten- tion (BI). Minor adjustments were made to the items, included changing 'technology' to 'SMHS', and 'psychological problems' to 'perceived self-reliance'. The full list of all questions can be found in table 2. In total, the questionnaire consisted of 25 items to be answered on a 5-point-Likert scale, were 1 represents 'totally disagree', and 5 represents 'totally agree', thus 3 indicating 'neither agree nor disagree'. All results were analysed via SPSS (IBM, 2017).

\subsection{Participants}

Participants were first contacted based on their indicated interest in a previous study (D'Haeseleer et al., $2019 b$ ). As only two of them were interested in participating, further recruitment was carried out via the snowball sampling method (Biernacki and Waldorf, 1981). Inclusion criteria stated that participants were above 65 years old, living independently at home or in a service flat, and not suffering from medical conditions that required specific clinical supervision. The study was approved by the Social and Societal Ethics Committee (G-S60250).

\subsection{Procedure}

Before starting the study, the researcher (first author) visited the older adults in their homes. She described the study design, and explained the information in the 


\begin{tabular}{lcclccccc} 
& & & \multicolumn{5}{c}{ Experiences with } & \\
\cline { 5 - 7 } code & gender & age & living area & tablet & computer & smartphone & wearables & owning wearables \\
\hline P01 & female & 67 & home with partner & few & few & none & none & none \\
P02 & male & 69 & home with partner & little & little & none & none & none \\
P03 & male & 66 & home with partner & little & little & few & a lot & ACT, HRM \\
P04 & male & 80 & home & little & little & little & none & none \\
P05 & female & 82 & flat & few & few & few & none & BPM \\
P06 & female & 71 & home with partner & few & little & none & none & BPM \\
P07 & female & 84 & flat & few & little & little & none & BPM \\
P08 & female & 78 & flat & none & few & few & none & BPM \\
P09 & female & 66 & home with partner & a lot & few & a lot & none & BPM \\
P10 & female & 74 & home with partner & none & little & none & none & none \\
P11 & male & 76 & home with partner & none & a lot & none & none & none \\
P12 & male & 66 & home with partner & none & little & few & little & BPM, ACT \\
P13 & female & 75 & home & none & none & none & little & BPM \\
P14 & female & 86 & flat & little & little & little & none & BPM \\
P15 & male & 84 & home with partner & a lot & a lot & a lot & none & BPM, ACT \\
P16 & female & 71 & home with partner & few & a lot & a lot & none & BPM
\end{tabular}

Table 1: Demographic and experience information on participants. Information of the wearables are indicated as activity (ACT), blood pressure monitor (BPM), and heart rate monitor (HRM).

informed consent. Participants were able to ask additional questions, and the researcher always had a tablet and one set of sensors with her, to show these to the participants.

Once someone agreed on participating in this study, a suitable starting date was chosen. This varied from starting the same day to one month later, depending on the availability of the participants and the schedule of the researcher. On the starting day, participants received a tablet with the web-application, along with the sensors. The researcher installed everything and showed the participants how to interact with the sensors and the application. Additionally, every participant was asked to conduct each task at least once, in order to get familiar with the technologies. Afterwards, participants were asked to fill out the UTAUT questionnaire for the first time (PRE). This evaluation polls for the users expectations of this SMHS.

Participants were asked to fill out a questionnaire at least every three days, and to use the sensors daily. The experiment lasted for two weeks. The researcher called the participant after one day, in order to check up on their experiences. Depending on the needs of the participant, the researcher made more frequent visits (this varied from only at the start and end of the study, to multiple times a week). Participants could always call the researcher when they needed extra support.

Finally, after two weeks had passed, the researcher went back to the participant's home, and a second
UTAUT questionnaire was taken (POST). In addition, a semi-structured interview was conducted where participants were asked about how they perceived using wearable sensors, and whether they were interested in using wearable sensors in the future. Moreover, the researcher also briefly asked participant about their overall experiences, what they liked and disliked.

\section{RESULTS}

In this section, we first present the results of the UTAUT questionnaire, alongside relevant excerpts from post-hoc interviews and observations. An overview of all individual UTAUT items, along with an overview of mean scores for each construct, Cronbach's alpha, and mean difference can be found in table 2. Next, we detail the data from the usage logs.

\subsection{Participants and Experience Data}

In total, 16 participants (median age $=74.5$ ) were recruited. Detailed information about the participants can be found in table 1. As expected, participants had never used an SMHS before. Five participants had little to no experience with using a computer, ten participants had little experience to no experience using a tablet before, and six participants never used a smartphone. 


\begin{tabular}{|c|c|c|c|c|c|}
\hline \multirow[b]{2}{*}{ Code } & \multirow[b]{2}{*}{ Construct and Item } & \multicolumn{2}{|c|}{$\begin{array}{l}\text { Cronbach's } \\
\text { Alpha }\end{array}$} & \multicolumn{2}{|c|}{ Mean (SD) } \\
\hline & & PRE & POST & PRE & POST \\
\hline $\mathbf{E E}$ & Effort Expectancy & .846 & .789 & $3.18(.915)$ & $3.79(.939)$ \\
\hline $\mathrm{EE}_{1}$ & The SMHS was clear and easy to understand. & & & $3.50(1.03)$ & $4.06(1.29)$ \\
\hline $\mathrm{EE}_{2}$ & Using the SMHS seems simple. & & & $3.38(1.15)$ & $4.00(1.16)$ \\
\hline $\mathrm{EE}_{3}^{*}$ & Using the SMHS seems complicated. & & & $2.94(1.34)$ & $3.62(1.50)$ \\
\hline $\mathrm{EE}_{4}^{*}$ & $\begin{array}{l}\text { Before I can/could use the SMHS, I still need/had to } \\
\text { learn a lot. }\end{array}$ & & & $2.13(1.09)$ & $3.19(1.38)$ \\
\hline $\mathrm{EE}_{5}$ & $\begin{array}{l}\text { I have sufficient technological knowledge (turning on/off } \\
\text { and charging the devices) to use the SMHS. }\end{array}$ & & & $3.94(1.18)$ & $4.06(.998)$ \\
\hline $\mathbf{P E}$ & Performance Expectancy & .891 & .927 & $3.75(.957)$ & $3.14(1.37)$ \\
\hline $\mathrm{PE}_{1}$ & $\begin{array}{l}\text { Using the SMHS would increase my perceived self- } \\
\text { reliance. }\end{array}$ & & & $3.88(1.15)$ & $3.19(1.38)$ \\
\hline $\mathrm{PE}_{2}$ & Using the SMHS would increase my personal wellbeing. & & & $3.63(1.03)$ & $3.13(1.41)$ \\
\hline $\mathrm{PE}_{3}$ & $\begin{array}{l}\text { The SMHS would increase my confidence to live inde- } \\
\text { pendently. }\end{array}$ & & & $3.63(1.20)$ & $3.31(1.62)$ \\
\hline $\mathrm{PE}_{4}$ & Using the SMHS would help me to age in place. & & & $3.88(1.03)$ & $2.94(1.61)$ \\
\hline SI & Social Influence & .517 & .574 & $3.72(.730)$ & $3.28(.894)$ \\
\hline $\mathrm{SI}_{1}$ & $\begin{array}{l}\text { If people in my care networks would know this SMHS, } \\
\text { they would be positive about it. }\end{array}$ & & & $3.87(.885)$ & $3.38(1.15)$ \\
\hline $\mathrm{SI}_{2}$ & $\begin{array}{l}\text { It people in my care network would know this SMHS, } \\
\text { they would advise me to use it. }\end{array}$ & & & $3.56(.892)$ & $3.19(.981)$ \\
\hline FC & Facilitating Conditions & .880 & .679 & $4.06(1.29)$ & $4.03(1.10)$ \\
\hline $\mathrm{FC}_{1}$ & $\begin{array}{l}\text { I own a computer or tablet, and could therefore use this } \\
\text { SMHS. }\end{array}$ & & & $3.81(1.52)$ & $3.88(1.41)$ \\
\hline $\mathrm{FC}_{2}$ & I have a reliable internet connection. & & & $4.31(1.20)$ & $4.19(1.11)$ \\
\hline $\mathbf{A N X}^{*}$ & Anxiety & .536 & .877 & $3.31(1.34)$ & $3.56(1.37)$ \\
\hline $\mathrm{ANX}_{1}^{*}$ & $\begin{array}{l}\text { I am afraid to make an irrevocable mistake when using } \\
\text { the internet. }\end{array}$ & & & $3.31(1.62)$ & $3.88(1.31)$ \\
\hline $\mathrm{ANX}_{2}^{*}$ & The internet sometimes feels like something threatening. & & & $3.31(1.62)$ & $3.25(1.57)$ \\
\hline SAF & Safety & .357 & .774 & $4.31(.911)$ & $3.66(1.30)$ \\
\hline $\mathrm{SAF}_{1}^{*}$ & $\begin{array}{l}\text { I am afraid that confidential information will fall into the } \\
\text { wrong hands. }\end{array}$ & & & $3.81(1.56)$ & $3.13(1.71)$ \\
\hline $\mathrm{SAF}_{2}$ & $\begin{array}{l}\text { I am confident that when I use the SMHS, that all infor- } \\
\text { mation will be treated strictly confident. }\end{array}$ & & & $4.81(.544)$ & $4.19(1.11)$ \\
\hline BI & Behavioural Intention & .828 & .804 & $2.86(.992)$ & $2.55(1.13)$ \\
\hline $\mathrm{BI}_{1}$ & $\begin{array}{l}\text { I would recommend the SMHS to others (older adults), } \\
\text { when they are still living independent at home. }\end{array}$ & & & $3.87(.957)$ & $3.75(1.29)$ \\
\hline $\mathrm{BI}_{2}$ & I would like to use this SMHS in the future. & & & $3.44(1.37)$ & $2.50(1.367)$ \\
\hline $\mathrm{BI}_{3}$ & $\begin{array}{l}\text { I would purchase this SMHS, if this would be commer- } \\
\text { cially available. }\end{array}$ & & & $3.00(1.21)$ & $2.44(1.41)$ \\
\hline $\mathrm{BI}_{4}$ & $\begin{array}{l}\text { How often do you think you would use this SMHS in the } \\
\text { future. (1: never, 2: once a month, 3: once a week, } 4 \text { : } \\
\text { twice or three times a week, 5: every day) }\end{array}$ & & & $1.13(1.31)$ & $1.50(1.59)$ \\
\hline
\end{tabular}

Table 2: UTAUT constructs and questions. All reversed items are marked with an asterix $\left(^{*}\right)$. 


\subsection{Evaluation UTAUT Constructs}

For each of the seven constructs, a reliability analysis (by means of Chronbach's alpha) was performed. Results of the average scores together with all individual items are pictured in table 2 . Results indicate that before starting the experiment, participants were neutral to positive towards using an SMHS. When analysing the results after the study, scores slightly decreased for all constructs, except for effort expectancy. Below, all constructs and average ratings, along with quotes from the interviews, are given.

Effort Expectancy. EE initially scored an average of $3.18(\mathrm{SD}=0.92)$ (on a scale from 1 to 5 ), thus close to neutral. After the study, this score increased to 3.79 ( $\mathrm{SD}=0.94$ ), indicating that older adults' perceived ease of use increased after the two-week study. These scores are in line with observations from the researcher who made the house visits. It was often noticed that at first, participants were afraid of having to use the tablet. However, after going through the application together, participants managed to use it independently.

P05: "In the beginning it is a bit overwhelming, but once you use it, it all goes very well." (day 2)

Performance Expectancy. PE scored initially 3.75 $(\mathrm{SD}=0.96)$ out of 5 , thus neutral to positive, but after the study this construct scored only $3.14(\mathrm{SD}=1.4)$, hence it decreased to a neutral score. This indicates that older adults found the application more useful at the beginning of the study compared to after using it for two weeks. Overall, participants found it interesting to follow up on their own health. Especially when using the sensors, often participants mentioned they gained new insights, and where happy to learn more about their activity, blood pressure, and/or sleep.

P16: "It is striking to see how much you sit down every day. Interesting to follow up on." (day 8)

Some participants were just curious, and did not feel the need to keep on using these sensors for a longer period.

P05: "I found it interesting to follow up on my sleep patterns. I was already familiar with my activities and blood pressure. But now I know, so I would not keep on using it." (day 14)

The blood pressure monitor was already used in advance by most participants. Others, who did not regularly take their blood pressure also indicated that they found it interesting to follow up. Although one person also reported that ambivalence, since noticing your blood pressure is too high can also make you worried.

P01: "I would find blood pressure measurement interesting, but because I have had a higher [cf. blood pressure] all day, it was rather worrying me." (day 13)

Social Influence. SI scored initially $3.72(\mathrm{SD}=0.73)$ out of 5 , thus neutral to positive, but after the study this construct decreased to 3.28 ( $\mathrm{SD}=0.89$ ). Participants often mentioned they did not really know what their friends/family or physicians would think about using such an SMHS, as this was never been discussed.

Facilitating Conditions. FC scored initially $4.06(\mathrm{SD}=1.3)$ out of 5 , thus positive, and after the study this construct scored still positive with $4.03(\mathrm{SD}=1.1)$. This is normal as the facilities of the person's home have not changed during the experiment. Almost every participant had access to either a tablet or a computer, although many of them did not use these. Also a wireless internet connection was often available at the participants' home, however, they had little knowledge on how this could be accessed. Luckily, in this study, mobile data cards were implemented in the tablets, so the tablet and sensors did not need to be attached to the network.

Anxiety. ANX scored initially $3.31 \quad(\mathrm{SD}=1.3)$ out of 5, thus neutral to positive, but after the study this score increased to $3.56(\mathrm{SD}=1.4)$. Note that items from this construct were reversed, thus a more positive response indicates that participants were less anxious towards using the internet. Overall, participants did not reported anxiety towards using the internet. However, we noticed that on the first day, participants were often afraid when using the tablet. Therefore, it was very important to take time to comfort them and let them understand they cannot do anything wrong.

P01: "So I just need to do this [cf. take blood
pressure with a blood pressure monitor] and
then I actually do not need to touch this [cf.
tablet]? [...] I am not going to use that [cf.
tablet]." (day 1)
P04: "I am afraid to do something wrong, or
to forget something." (day 1$)$

Safety. SAF scored initially $4.13(\mathrm{SD}=0.91)$ out of 5 , thus positive, but after the study this construct scored $3.66(\mathrm{SD}=1.3)$ which is neutral to positive. Nobody had problems with sharing this sensitive information, 
as this was a research study. In this study, privacy issues from commercial systems were not explicitly discussed, but in one interview the participant mentioned that she had no problem in sharing information, as this was already also the case with smartphones (cf. Android from Google) and online advertising.

P09: "Privacy? I have no problems with privacy. Then you should look at Google and all their advertising." (day 15)

Behavioural Intention. BI scored initially 2.86 $(\mathrm{SD}=0.99)$ out of 5 , thus negative to neutral, but after the study this construct scored only 2.55 ( $\mathrm{SD}=0.94$ ), meaning it further decreased. Participants did utter to find the application useful, however, it was mentioned multiple times that they would not (yet) need it themselves, as they were still in good health.

P09: "Those questionnaires in particular can be of interest to single elderly people [cf. she is still living together with her husband]. Certainly if that would be mandatory and the physicians also support it." (day 15)

Participants quickly got used to the application and the sensors. Using the sensors became a habit for most of them. At the same time, at the end of the study, some mentioned they would "not be missing the sensors".

P05: "It went very quickly to get used to the sensors. However, this system is not for me, I do not need it yet. Moreover, I would rather not become a 'slave' of all those devices." (day 14)

\subsection{SMHS Usage Data}

Each participant used the application during a twoweek study, varying from 13 to 16 days, depending on the availability of the person. Participants were asked to wear an activity tracker every day, to measure their blood pressure at least once a day, and to use a sleep monitor every night. Figure 4 gives an overview of how participants interacted with the SMHS. Note that all data has been rescaled to the same period, to increase readability. In addition, for each person, a gray line indicates the exact length of participation in the study. For each participants, all sensor and/or questionnaire interactions are pictured.

Questionnaires. Since every participant was asked to complete a full set of questionnaires (12 categories) every three days, and to use the sensors daily, ideally this would result in five complete sets, totaling
60 categories. This was only achieved by one participant (P08). In contrast, participant P13 quit after eight days, completing only nine categories. Four participants stopped filling out questionnaires after seven to ten days, the other twelve participants completed between 36 and 52 categories throughout the entire study period. Data results, aggregated over all participants, show that each category was completed 53 to 68 times throughout the two week study period. In order of importance, the following categories were answered most frequently: emotional role functioning, sleep, social functioning, mental health, and meals.

Activity Tracker. The activity tracker was used by 15 out of 16 participants. Figure 4 represents a timeline of participants' activities, i.e., walking, cycling, running, sitting, or standing, where at least one activity was measured during a five-minute block. The gaps during the night indicate that participants were not wearing their tracker when they were sleeping. From all participants, one person (P01) did not wear an activity tracker, as she felt her outfit did not allow to attach the sensor. Two participants (P02, P15) stopped wearing the tracker for at least a week within the study, and one participant (P13) only wore the tracker for ten consecutive days. Presumable these participants forgot to charge the battery. The other 12 participants wore the activity tracker daily.

Sleep Monitor. The sleep monitor was used by 14 out of 16 participants. One participant (P13) was afraid of using the sleep monitor during the night as she also had an electrical blanket on top of the mattress and therefore excluded this sensor. Another participant (P16) preferred not to use the sleep monitor. The other participants used the sleep monitor, if possible, as often participants reported troubles getting data out of the sensor. Because the support for the type of sleep monitor used in this study, 'Beddit' (Beddit, 2016), was discontinued, problems occured when pairing the device. For the first six participants, the sleep monitor was either disfunctional or taken away for replacement, indicating one to three nights without measurements. For participant P07, 10 out of 14 nights, the sleep monitor was disfunctional. For participant P09 to P12 the sleep was not registered during one to five nights. While testing with participants P14 and P15, the integration between the sensors and the platform was disfunctional and therefore did not register for respectively 11 and 14 days.

Blood Pressure Monitor. The blood pressure monitor was used by all participants. Since some extra measurements were due to an error in the syncing 


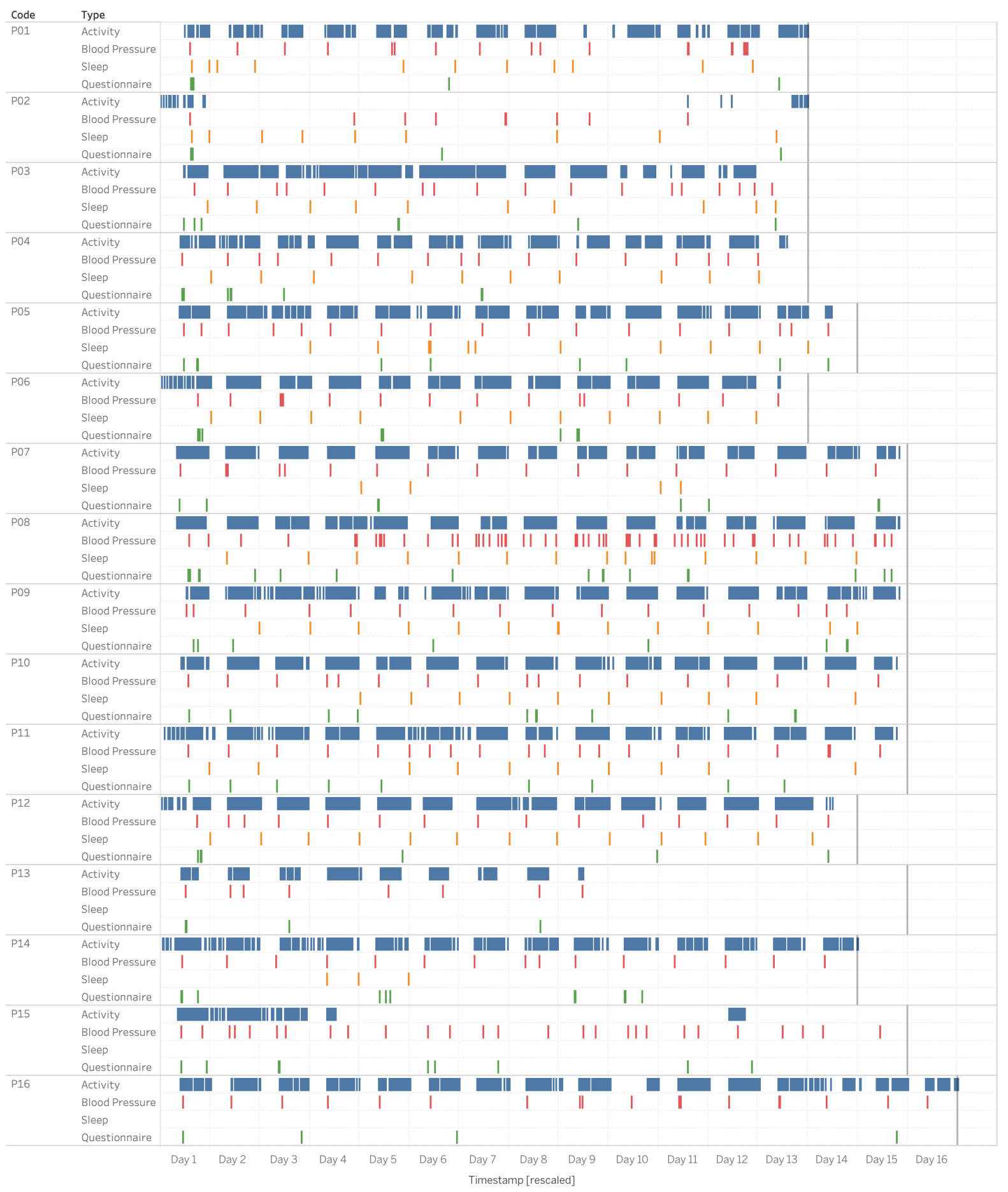

Type

Blood Pressure

Sleep

Questionnaire

Figure 4: Usage data from all participants during the two-week experiment. 
process, the measurements that were taken within 5 min of each other were excluded in this analysis. One participant (P13) only used the blood pressure monitor eight times. This was due to the inability of the person to attach the strap of the measurement device by herself. Therefore, measurements were only taken when an additional visitor came by. Participant P08 was an exception, as she took her blood pressure 69 times during the 15 days. In general, on average, participants took their blood pressure one to two times a day.

\section{DISCUSSION}

This study aimed to investigate whether healthy community dwellers, aged 65+, were ready to adopt an SMHS in a real-world home environment. Prior to use all determinants of use and acceptance of SMHS in our study were neutral to positive: effort expectancy (EE), performance expectancy (PE), social influence (SI), facilitating conditions (FC), anxiety (ANX), and safety (SAF). Post use, all values (except for EE and FC) decreased. Moreover, post use, older adults' behavioural intention (BI) scored only an average score of $2.55(\mathrm{SD}=1.1)$.

Reflection on SMHS. Our findings contrasts with the study from Doyle et al. (Doyle et al., 2014), which is perhaps most akin to our study setup. Several hypotheses can be put forward. This may be due to the specific SMHS design. This may also be attributed to the use of a different methodology in polling for adoption. Finally, the different results may also be due to the fact that the average age of participants in our study is older. Studies suggest the older the participants, the less motivated they are to use interactive health technologies such as a tracker (McMahon et al., 2016). Similar to Doyle's findings, however, we found that older adults like to have freedom in personalisation, in our case determining which healthrelated themes they find interesting.

Reflection on UTAUT model. In this study, we relied on the theoretical model of Venkatesh, et al. (Venkatesh et al., 2003) in order to predict technology acceptance. This UTAUT model suggests that measurements on the constructs EE, PE, FC, and SI predict BI, in particular, positive scores on the aforementioned drivers should also result in a positive score for BI. Surprisingly, this was not confirmed in our results. Research from Peek et al. may provide extra insights, as they investigated motivators for older adults in order to use (new) technologies, as well as impact of changes and stability of use (Peek et al., 2016; Peek et al., 2017; Peek et al., 2019). This Cycle of Technology Acquirement by Independent-Living Seniors (C-TAILS) model gives an overview of many different influential factors in technology adoption by older adults, including the importance of support by friends or family, which is weighted strongly. This is in line with our findings, as the construct social influence from friends/family or physicians scored rather low (neutral) post use.

Similar findings were also reported in (D'Haeseleer et al., 2019a), where authors found that older adults lack the perceived value of SMHS, and did not welcome the accompanying shift from curative to preventive care (Vines et al., 2015). Here, authors emphasised that older adults will not use SMHS, or interactive technologies in general, unless they find it irrefutably useful. This finding is echoed in this study, as older adults did mention to find the SMHS useful (PE), but simply not for them. They did not (yet) see the benefits of using SMHS themselves.

\section{CONCLUSION}

In this study, we report on the uses and attitudes of 16 healthy participants aged over 65. During a two week study, participants used an SMHS in a real world setting, at home. An adapted version of Unified Theory of Use and Acceptance for Technology (UTAUT) was used to measure acceptance, both pre and post, towards an SMHS (De Witte and Van Daele, 2017; Venkatesh et al., 2003). In addition, usage data was explored, as well as a post-hoc interview with the participants. Results indicate that participants did find the application user-friendly and felt confident in using the application. They also had access to a computer or tablet with internet access. Despite these positive aspects, they did not see the benefits of following up on their own health regularly, and their behavioural intention decreased even more after the two-week study.

However, only one SMHS was tested in this study, with a limited sample. Therefore, future research is needed to investigate whether these results can be generalised to other SMHS, and a broader group of older adults aged $65+$.

\section{ACKNOWLEDGEMENTS}

We would like to thank all users for their participation. This research study was possible with the support of KIC EIT funding for GRACE-AGE. 


\section{REFERENCES}

Activ8 (2016). Activ8 Professional validation - Activ8all.com.

A\&DCompany (2016). Clinical Validation | Medical | Products $\mid$ A\&D.

Baumeister, H., Nowoczin, L., Lin, J., Seifferth, H., Seufert, J., Laubner, K., and Ebert, D. D. (2014). Impact of an acceptance facilitating intervention on diabetes patients acceptance of internet-based interventions for depression: a randomized controlled trial. Diabetes research and clinical practice, 105(1):30-39.

Beddit (2016). Beddit Sleep Tracker.

Biernacki, P. and Waldorf, D. (1981). Snowball sampling: Problems and techniques of chain referral sampling. Sociological methods \& research, 10(2):141-163.

Buckingham, C. D. (2016). GRiST - Galatean Risk and Safety Tool.

Champion, V. L., Skinner, C. S., et al. (2008). The health belief model. Health behavior and health education: Theory, research, and practice, 4:45-65.

Cimperman, M., Brenčič, M. M., and Trkman, P. (2016). Analyzing older users home telehealth services acceptance behaviorapplying an extended utaut model. International journal of medical informatics, 90:22-31.

Davis, F. D. (1985). A Technology Acceptance Model for Empirically Testing New End-user Information Systems: Theory and Results. Massachusetts Institute of Technology, Sloan School of Management, https://dspace.mit.edu/handle/1721.1/15192. GoogleBooks-ID: hbx8NwAACAAJ.

De Witte, N. and Van Daele, T. (2017). Vlaamse UTAUTvragenlijst.

Deci, E. L. and Ryan, R. M. (2012). Self-determination theory. Handbook of theories of social psychology.

D'Haeseleer, I., Gerling, K., Schreurs, D., Buckingham, C., Abeele, V., et al. (2019a). Uses and attitudes of old and oldest adults towards self-monitoring health systems. In Pervasive Health, Date: 2019/05/202019/05/23, Location: Trento, Italy.

D'Haeseleer, I., Gerling, K., Schreurs, D., Vanrumste, B., and Vanden Abeele, V. (2019b). Ageing is not a disease: Pitfalls for the acceptance of self-management health systems supporting healthy ageing. In The 21st International ACM SIGACCESS Conference on Computers and Accessibility, pages 286-298. ACM.

Doyle, J., Walsh, L., Sassu, A., and McDonagh, T. (2014). Designing a Wellness Self-management Tool for Older Adults: Results from a Field Trial of YourWellness. In Proceedings of the 8th International Conference on Pervasive Computing Technologies for Healthcare, PervasiveHealth '14, pages 134141, ICST, Brussels, Belgium, Belgium. ICST (Institute for Computer Sciences, Social-Informatics and Telecommunications Engineering).

Ebert, D. D., Berking, M., Cuijpers, P., Lehr, D., Pörtner, M., and Baumeister, H. (2015). Increasing the acceptance of internet-based mental health interventions in primary care patients with depressive symptoms. a randomized controlled trial. Journal of affective disorders, 176:9-17.

Fishbein, M. (1979). A theory of reasoned action: some applications and implications. In Nebraska Symposium on Motivation. University of Nebraska Press.

Fougeyrollas, P. and Noreau, L. (2001). Life Habits.

Heart, T. and Kalderon, E. (2013). Older adults: Are they ready to adopt health-related ICT? International Journal of Medical Informatics, 82(11):e209-e231.

IBM (2017). Ibm spss statistics.

iHealth Labs Inc. (2019). ihealth. (Accessed on 01/03/2020)

Innovations, B. (2016). BeWell Innovations.

Jaschinski, C. (2014). Ambient Assisted Living: Towards a Model of Technology Adoption and Use Among Elderly Users. In Proceedings of the 2014 ACM International Joint Conference on Pervasive and Ubiquitous Computing: Adjunct Publication, UbiComp '14 Adjunct, pages 319-324, New York, NY, USA. ACM.

Jaschinski, C. and Allouch, S. B. (2015). Understanding the users acceptance of a sensor-based ambient assisted living application. In Human Behavior Understanding, pages 13-25. Springer.

Jiménez-Mixco, V., Cabrera-Umpiérrez, M. F., Arrendondo, M. T., Panou, M., Struck, M., and Bonfiglio, S. (2013). Feasibility of a wireless health monitoring system for prevention and health assessment of elderly people. In 2013 35th Annual International Conference of the IEEE Engineering in Medicine and Biology Society $(E M B C)$, pages 7306-7309, Osaka, Japan. IEEE.

Khechine, H., Lakhal, S., and Ndjambou, P. (2016). A meta-analysis of the utaut model: Eleven years later. Canadian Journal of Administrative Sciences/Revue Canadienne des Sciences de l'Administration, 33(2):138-152.

Kononova, A., Li, L., Kamp, K., Bowen, M., Rikard, R. Cotten, S., and Peng, W. (2019). The use of wearable activity trackers among older adults: Focus group study of tracker perceptions, motivators, and barriers in the maintenance stage of behavior change. JMIR mHealth and uHealth, 7(4):e9832.

Lemmens, J., Ism van Engelen, E., Post, M. W., de Witte, L. P., Beurskens, A., Wolters, P. M., and de Witte, L. P. (2007). Reproducibility and validity of the dutch life habits questionnaire (life-h 3.0) in older adults. Clinical rehabilitation, 21(9):853-862.

Lumos Labs, I. (2020). Lumosity brain training. (Accessed on $01 / 03 / 2020$ ).

McMahon, S. K., Lewis, B., Oakes, M., Guan, W., Wyman, J. F., and Rothman, A. J. (2016). Older adults experiences using a commercially available monitor to self-track their physical activity. JMIR mHealth and uHealth, 4(2):e35.

Nations, U. (2015). World Population Prospects - Population Division - United Nations.

Nunes, F., Verdezoto, N., Fitzpatrick, G., Kyng, M., Grönvall, E., and Storni, C. (2015). Self-care technologies in hci: Trends, tensions, and opportunities. ACM Transactions on Computer-Human Interaction (TOCHI), 22(6): 1-45. 
Peek, S., Luijkx, K., Vrijhoef, H., Nieboer, M., Aarts, S., Van Der Voort, C., Rijnaard, M., and Wouters, E. (2017). Origins and consequences of technology acquirement by independent-living seniors: towards an integrative model. BMC geriatrics, 17(1):189.

Peek, S. T., Luijkx, K., Vrijhoef, H., Nieboer, M., Aarts, S., van der Voort, C., Rijnaard, M., and Wouters, E. (2019). Understanding changes and stability in the long-term use of technologies by seniors who are aging in place: a dynamical framework. BMC geriatrics, 19(1):1-13.

Peek, S. T., Luijkx, K. G., Rijnaard, M. D., Nieboer, M. E., van der Voort, C. S., Aarts, S., van Hoof, J., Vrijhoef, H. J., and Wouters, E. J. (2016). Older adults' reasons for using technology while aging in place. Gerontology, 62(2):226-237.

Queirós, A., Cerqueira, M., Santos, M., and Rocha, N. P. (2017). Mobile health to support ageing in place: A synoptic overview. Procedia computer science, 121:206-211.

Sintonen, S. and Immonen, M. (2013). Telecare services for aging people: Assessment of critical factors influencing the adoption intention. Computers in Human Behavior, 29(4):1307-1317.

Taiwo, A. A. and Downe, A. G. (2013). The theory of user acceptance and use of technology (utaut): A metaanalytic review of empirical findings. Journal of Theoretical \& Applied Information Technology, 49(1).

Van der Zee, K. and Sanderman, R. (1993). Rand-36. Groningen: Northern Centre for Health Care Research, University of Groningen, the Netherlands, 28:6.

Vanneste, D., Vermeulen, B., and Declercq, A. (2013). Healthcare professionals acceptance of BelRAI, a web-based system enabling person-centred recording and data sharing across care settings with interRAI instruments: a UTAUT analysis. BMC Medical Informatics and Decision Making, 13(1).

Venkatesh, V., Morris, M. G., Davis, G. B., and Davis, F. D. (2003). User Acceptance of Information Technology: Toward a Unified View. MIS Quarterly, 27(3):425478.

Verdezoto, N. and Grönvall, E. (2016). On preventive blood pressure self-monitoring at home. Cognition, Technology \& Work, 18(2):267-285.

Vines, J., Pritchard, G., Wright, P., Olivier, P., and Brittain, K. (2015). An Age-Old Problem: Examining the Discourses of Ageing in HCI and Strategies for Future Research. ACM Trans. Comput.-Hum. Interact., 22(1):2:1-2:27.

Walters, S. J., Munro, J. F., and Brazier, J. E. (2001). Using the sf-36 with older adults: a cross-sectional community-based survey. Age and ageing, 30(4):337343.

Wang, J., Du, Y., Coleman, D., Peck, M., Myneni, S., Kang, H., and Gong, Y. (2019). Mobile and connected health technology needs for older adults aging in place: Cross-sectional survey study. JMIR Aging, 2(1):e13864
Ware, J. E. and Sherbourne, C. D. (1992). RAND-36 item Health Survey.

Young, R., Willis, E., Cameron, G., and Geana, M. (2013). Willing but Unwilling: Attitudinal barriers to adoption of home-based health information technology among older adults:. Health Informatics Journal. 